\title{
A ÉTICA E A MORALIDADE NOS ORGÃOS AMBIENTAIS NA CONCESSÃO DAS LICENÇAS E ALVARÁS PARA A CONSTRUÇÃO CIVIL
}

\section{ETHICS AND MORALITY IN ENVIRONMENTAL ORGANS IN LICENSING AND ALVARAS CONCESSION FOR CIVIL CONSTRUCTION}

\begin{abstract}
DEBORA CRISTINA DE CASTRO DA ROCHA
Mestranda em Direito Empresarial e Cidadania pelo UNICURITIBA e pós-graduanda em Direito Imobiliário pela Escola Paulista de Direito. Especialista em Direito e Processo do Trabalho e em Direito Constitucional pela Academia Brasileira de Direito Constitucional. Professora de Direito e Processo do Trabalho, pesquisadora do CNPQ pelo Centro Universitário Curitiba nos grupos de pesquisa "Reforma Trabalhista" e "Responsabilidade e Função Social da Empresa", Presidente da Comissão de Direito Imobiliário OAB/SJP, Vice-Presidente da Comissão de Fiscalização, Ética e Prerrogativas OAB/SJP e integrante da Comissão de Direito Imobiliário OAB/PR. Advogada.

\section{EDILSON SANTOS DA ROCHA}

Pós-graduando em Direito Imobiliário pela Escola Paulista de Direito e pesquisador CNPQ pelo Centro Universitário Curitiba nos grupos de pesquisa "Reforma Trabalhista", "Compliance" e "Responsabilidade e Função Social da Empresa". Graduado em Tecnologia em Fabricação Mecânica pelo Ensitec, acadêmico de Direito pela Faculdade da Indústria,
\end{abstract}


Personalidade Acadêmica Homenageada:

Carlos Aurélio Mota de Souza (Universidade Ibirapuera - UNIB)

\section{RESUMO}

Esta pesquisa tem como objetivo principal, sob uma perspectiva ética e moral, discutir a gestão de impactos ambientais advindos da construção civil em grandes empreendimentos imobiliários. E ainda, evidenciar os planos e programas ambientais, analisar as causas e consequências dos desvios de finalidade do gestor e não conformidades, descrever os riscos, os impactos ambientais e desafios relacionados às práticas de atos de improbidade na gestão ambiental, principalmente, no que diz respeito à concessão de alvarás em descompasso com os requisitos legais exigidos, gerando impactos desastrosos ao meio ambiente e à sociedade.

PALAVRAS-CHAVE: Gestão Ambiental; Ética; Moral; Atos de Improbidade.

\section{ABSTRACT}

This research has as main objective, from an ethical and moral perspective, to discuss the management of environmental impacts arising from construction in large real estate projects. Also, to highlight the environmental plans and programs, to indicate the causes and consequences of managerial deviations and nonconformities, to describe the risks, the environmental impacts and challenges related to the practices of acts of improbity in environmental management, respect to the concession of permits in disrepair with the required legal requirements, generating disastrous impacts to the environment and society.

KEYWORDS: Ethics, Morals, Environmental Management, Acts of Impropriety.

\section{INTRODUÇÃO}

As ações humanas são resultados da convivência entre o homem e o local em que vive, sendo necessário retirar do ambiente os recursos naturais disponíveis 


\section{Personalidade Acadêmica Homenageada:}

Carlos Aurélio Mota de Souza (Universidade Ibirapuera - UNIB)

visando a sua utilização da nos seus mais variados aspectos. Quando se fala em atividades humanas, não há como deixar de evidenciar a construção civil.

Todavia, para o desenvolvimento de quaisquer atividades, especialmente as relacionadas com a construção civil, indissociável a ideia de sustentabilidade, a fim de que seja garantida a manutenção dos recursos naturais, bem como da qualidade ambiental para as atuais e futuras gerações.

É neste cenário que sobrevém o licenciamento ambiental, para que se harmonize a realização de todas as realizações que virão a ser desenvolvidas de forma sustentável. O licenciamento tem por escopo auxiliar o poder público à visualização do conjunto, propiciando conhecer todas as atividades que utilizam recursos naturais e podem gerar impactos no meio ambiente em uma determinada região.

O licenciamento se apresenta como uma ferramenta de gestão dos órgãos competentes que têm como meta agir de forma preventiva em prol da proteção do meio ambiente, bem comum da sociedade. Além disso, se consubstancia como um dos meios de atuação da Política Nacional do Meio Ambiente, caracterizado como procedimento administrativo destinado à licenciar atividades ou empreendimentos que se utilizam de recursos ambientais, efetiva ou potencialmente poluidores ou capazes, sob qualquer forma, de ensejar a degradação ambiental.

No processo de licenciamento, os órgãos ambientais em âmbito federal, estadual e municipal, trabalham na avaliação dos impactos que cada empreendimento causa ou poderá causar ao meio ambiente, analisando a sua viabilidade ambiental e o seu enquadramento às normas ambientais aplicáveis. Consiste em obrigação da iniciativa privada buscar a licença ambiental junto ao órgão competente, desde o início do planejamento do empreendimento, que perpassa pela sua instalação até o início efetivo da operação. Sob essa perspectiva, tem-se que o licenciamento ambiental se destaca como um importante diálogo entre a empresa e o órgão ambiental.

Quando o assunto é a construção civil, não se pode esquecer de analisar previamente questões relacionadas ao urbanismo e ao uso e ocupação do solo, 


\section{Personalidade Acadêmica Homenageada:}

Carlos Aurélio Mota de Souza (Universidade Ibirapuera - UNIB)

conjuntamente com os aspectos ambientais que não raro podem inviabilizar determinadas intervenções humanas.

Em nosso país, a criação e a implementação de legislações e políticas públicas têm possibilitado o surgimento de distintas trajetórias de desenvolvimento, as quais são constituídas de conjunturas umbilicalmente relacionadas à concepção de crescimento econômico. Daí porque, esforços têm sido promovidos com vistas à pressionar governos e empresas a adequarem-se à esse novo cenário.

Todavia, pela complexidade da situação tornou-se imprescindível a criação de políticas mitigadoras dos impactos produzidos pelo desenvolvimento, uma vez que, a despeito dos imensos benefícios dele decorrentes, não se pode olvidar da geração do desequilíbrio do ambiente natural. Justamente em decorrência lógica dessa situação, ainda na década de 1980, fora instituída a Política Nacional do Meio Ambiente (PNMA - Lei 6.938/1981) com vistas à "compatibilização do desenvolvimento econômico-social com a preservação da qualidade do meio ambiente e do equilíbrio ecológico".

Contudo, se a mudança política aliada à criação de melhores legislações, não estiver acompanhada de técnicas e instrumentos melhorados frequentemente, o resultado acaba não sendo o esperado. Essa situação acaba desaguando no licenciamento ambiental, quando são evidenciados inúmeros conflitos provenientes, de um lado, de decisões objetivando o avanço social primando-se por resguardar o meio ambiente, e de outro, de situações provenientes de irregularidades nas concessões de licenças amparadas em atos de improbidade na gestão ambiental.

Diante desse panorama, pretende-se explorar o universo do processo de licenciamento ambiental na construção civil, com olhar direcionado aos impactos decorrentes das irregularidades e suas consequências ao meio ambiente. Objetivase, desse modo, compreender a tônica dessa controvérsia, sob uma perspectiva ética e moral, fulcrada nos empreendimentos imobiliários, que após as concessões irregulares de licenças são embargados sob o argumento da proteção ambiental. 


\section{Personalidade Acadêmica Homenageada:}

Carlos Aurélio Mota de Souza (Universidade Ibirapuera - UNIB)

\section{O LICENCIAMENTO AMBIENTAL E ESTUDO DE IMPACTO AMBIENTAL}

\subsection{LICENCIAMENTO AMBIENTAL NO BRASIL}

O licenciamento ambiental está fulcrado no princípio da proteção, da precaução ou da cautela, fundamental do direito ambiental, que veio consignado na Declaração do Rio, de 1992 (princípio 15). Integra a tutela administrativa de prevenção. Objetiva à preservação seja por meio da prevenção da ocorrência de impactos negativos ao meio ambiente, seja mitigando-os ao máximo com a imposição de condicionantes ao exercício da atividade ou a construção do empreendimento, de modo a alcançar o primeiro objetivo da Política Nacional do Meio Ambiente, ou seja, conciliar o desenvolvimento econômico com a preservação.

Todavia, o Licenciamento Ambiental já havia sido previsto na Lei $\mathrm{n}$. 6.938/81, em seu artigo 9을 inciso IV, como um das ferramentas da Política Nacional do Meio Ambiente. A Resolução CONAMA 237/97, determinou que o órgão do SISNAMA é que verificará quando da necessidade das licenças ambientais específicas de acordo com a natureza, características e peculiaridades das atividades ou empreendimentos a serem realizados, que tenham potencial para interferir no meio ambiente.

O texto Constitucional brasileiro outorga o exercício livre de atividades econômicas, logo, o Poder Público deverá intervir quando embasado por lei que determine essa intervenção, pois, a atividade econômica não poderá ser simplesmente cerceada. Quando se entrelaçam, desenvolvimento econômico e meio ambiente deve haver a intervenção, tendo em vista todo o estudo e a constatação de que o meio ambiente não é um bem inesgotável, é passível de ser exaurido. Esta verdade absoluta é vislumbrada por quase todo o mundo.

O Licenciamento Ambiental é ato complexo que envolve vários agentes e deve ser precedido do EIA/RIMA, que constatará a significância do impacto que será causado pelo empreendimento. Na Resolução CONAMA, consignam os tipos de Licenças Ambientais, que são: Licença Prévia (LP), Licença de Instalação (LI) e Licença de Operação (LO). 


\section{Personalidade Acadêmica Homenageada:}

Carlos Aurélio Mota de Souza (Universidade Ibirapuera - UNIB)

A indispensabilidade de profissionais habilitados para o licenciamento ambiental é medida que se estabelece ante a importância de serem amparados os potenciais naturais. A mera ameaça de dano ao meio ambiente é considerável para que sejam tomadas todas as providências imprescindíveis a evitar sua materialização. Isso ocorre tanto pela importância que o meio ambiente adquiriu no ordenamento constitucional constituído com a Constituição de 1988, quanto da irredutibilidade e gravidade dos danos, e envolve, até mesmo, a interrupção de empreendimentos que, pela sua grandeza, possam provocar em significativo dano ambiental, ainda que este não esteja cuidadosamente corroborado pelos órgãos de proteção.

Designa também no artigo $5^{\circ}$, as orientações gerais necessárias, que na acepção de Sirvinskas, são: "a) contemplar todas as alternativas tecnológicas e de localização do projeto, confrontando-as com a hipótese de não execução do projeto; b) identificar e avaliar sistematicamente os impactos ambientais gerados nas fases de implantação e operação da atividade; c) definir os limites da área geográfica a ser direta ou indiretamente afetada pelos impactos, denominada área de influência do projeto, considerando, em todos os casos, a bacia hidrográfica na qual se localiza; e d) considerar os planos e programas governamentais propostos e em implantação na área de influência do projeto e sua compatibilidade." (SIRVINSKAS, 2008, p. 153).

Toda a operação que possa produzir algum prejuízo ao meio ambiente terá como condição o licenciamento ambiental. Essas atividades estão relacionadas nos anexos da Resolução CONAMA n.. 237/97. Sinteticamente são elas: depósitos; indústrias de qualquer porte; criação animal; atividades de parcelamento do solo; irrigação; lavanderias, obras civis; atividades que envolvam resíduos; cemitérios; serviços de utilidade como o tratamento de água e esgoto; usinas termelétricas; recondicionamento de pneumáticos; hidrelétricas; energia eólica; portos; terminais; complexos de lazer; pista de corrida; forno de carvão; vegetal ou químicos; comércio de agrotóxicos; de produtos de origem mineral; postos de combustíveis e lavagem; laboratórios; restaurantes; lanchonetes; hospitais e clínicas. 


\section{Personalidade Acadêmica Homenageada:}

Carlos Aurélio Mota de Souza (Universidade Ibirapuera - UNIB)

A inexistência de licença qualifica crime mencionado na Lei $n . .9605 / 98$, que ordena sobre as cominações penais e administrativas para as práticas danosas ao Meio Ambiente. A despeito do rol que trás a Resolução CONAMA, n.ำ 237/97, há operações que não se submetem ao Licenciamento Ambiental. Podemos aludir José Carlos Barbieri que aduz que nem toda a atividade ou empreendimento estão sujeitos ao licenciamento ambiental. A Resolução CONAMA 237/97 enumera as atividades ou empreendimentos sujeitos ao licenciamento ambiental, mas trata-se de uma lista não exaustiva, pois incumbe ao órgão ambiental competente estabelecer os parâmetros de exigibilidade, o detalhamento e a suplementação desse repertório, tendo em vista as especialidades, os riscos ambientais, 0 porte e outras particularidades do empreendimento ou atividade. (BARBIERI, 2007, p. 293).

A competência para a outorga das licenças ambientais é dos órgãos que constituem o SISNAMA, retratados no artigo $6^{\circ}$, da Lei $n . \stackrel{0}{6.938 / 81}$. Em regra a compete ao órgão público estadual. O CONAMA define as normas gerais para a concessão. Na Resolução n. 237/97, artigo 4ํㅡ, estão normas regras gerais, "compete ao SISNAMA, o licenciamento ambiental, que se refere o artigo 10 da Lei n. $.6 .938 / 81$, de empreendimentos e atividades com significativo impacto ambiental de âmbito nacional ou regional" e na Resolução n. ${ }^{\circ}$ 001/86, artigo $2^{\circ}$, estão estabelecidas as modalidades e termos de validade, além do mais as hipóteses de derrogação das licenças outorgadas, "Dependerá de elaboração de Estudo de Impacto Ambiental (EIA) e respectivo Relatório de Impacto Ambiental (RIMA), a ser submetido à aprovação do órgão estadual competente e do IBAMA, em caráter supletivo, o licenciamento de atividades modificadoras do meio ambiente". (BRASIL, CONAMA, 1986).

Faz-se imprescindível fazer um adendo por haver em certos casos desacordos de competência. Podemos mencionar, por exemplo, quando o IBAMA se diz competente para outorgar a licença quando está abrangido potencial risco de devastação ambiental a bem da União e órgão estadual refutarem essa exposição. Em tais hipóteses faz-se indispensável parecer do Ministério do Meio Ambiente ou da Advocacia Geral da União para elucidar o impasse e estipular qual órgão outorgara a licença. 


\section{Personalidade Acadêmica Homenageada:}

Carlos Aurélio Mota de Souza (Universidade Ibirapuera - UNIB)

Certo é que ao IBAMA são conferidas as seguintes convenções: exercer a política florestal estipulada pelo Ministério do Meio Ambiente; recomendar medidas legais e técnicas para o aperfeiçoamento da política de prestimosidade dos recursos florestais; organizar o aproveitamento dos recursos florestais; propiciar, realizar, fazer, executar e avaliar os inventários florestais e projetos de manejo florestal sustentável de florestas nativas; providenciar o aproveitamento sustentável e variações de recursos florestais; ministrar assistência técnica aos estados, municípios, entidades civis e organizações não governamentais, no que tange à estruturação dos recursos florestais; conduzir e supervisionar as atividades de manejo dos recursos florestais, produzidas conjuntamente às representações do IBAMA nos Estados. (BRASIL, CONAMA, 1986).

\subsection{ESTUDO DE IMPACTO AMBIENTAL}

O Estudo de Impacto Ambiental (EIA) foi estabelecido dentro da Política Nacional do Meio Ambiente, por intermédio da Resolução CONAMA, n. $.001 / 86$ de 23 de janeiro de 1986. É título técnico, onde são estimadas as repercussões para o ambiente resultantes de certo projeto. Nele deparam-se designados e examinados de forma equânime e técnica os impactos que um determinado projeto poderá provocar no ambiente, igualmente expor providências para reduzir os prováveis impactos.

O estudo prévio de impacto ambiental (EPIA) é um dos mecanismos da política nacional do meio ambiente, tão significativo quanto o zoneamento para a amparo do ambiente. É um instrumento administrativo preemptivo. Por esse motivo é

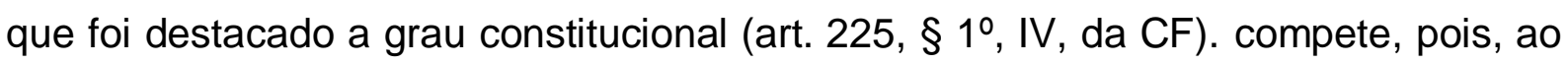
Poder Público reivindicar, na forma da lei, para instauração de obra ou atividade presumivelmente ocasionadora de expressiva degradação do meio ambiente, estudo prévio de impacto ambiental, a que se dará publicidade. Dessa forma, o método de licenciamento ambiental deverá ser antevertido do estudo prévio de impacto ambiental (EPIA) e do seu devido relatório de impacto ambiental (RIMA). Exigir-se-á o EPIA quando a atividade for potencialmente causadora de significativa degradação 


\title{
Personalidade Acadêmica Homenageada:
}

Carlos Aurélio Mota de Souza (Universidade Ibirapuera - UNIB)

ambiental. Entende-se por significativa degradação ambiental toda modificação ou alteração substancial e negativa do meio ambiente, causando dano extenso à flora, à fauna, às águas, ao ar e à saúde humana (SIRVINSKAS, 2008, p. 148).

O intuito de se estudar os impactos é o de mensurar as repercussões das ações, para prevenir os riscos ao meio ambiente em consequência da execução dos projetos. Está mencionado no artigo 225, § 1ํ, inciso IV da Constituição Federal.

Deve obedecer ao que impõe a Lei da Política Nacional do Meio Ambiente, que estão arrolados no artigo 5ํํㄹ da Resolução CONAMA n.․ 001/86:

\begin{abstract}
Artigo $5^{\circ}$ - $O$ estudo de impacto ambiental, além de atender a legislação, em especial os princípios e objetivos expressos da Lei de Política Nacional do Meio Ambiente, obedecerá as seguintes diretrizes gerais: I - Contemplar todas as alternativas tecnológicas e de localização de projeto, confrontandoas com a hipótese de não execução do projeto; II - Identificar e avaliar sistematicamente os impactos ambientais gerados nas fases de implantação e operação da atividade; III - Definir os limites da área geográfica a ser direta ou indiretamente afetada pelos impactos, denominada área de influência do projeto, considerando, em todos os casos, a bacia hidrográfica na qual se localiza; IV - Considerar os planos e programas governamentais, propostos e em implantação na área de influência do projeto, e sua compatibilidade."( BRASIL, CONAMA, 1986).
\end{abstract}

Verificando-se qualquer interesse específico local, o Poder Público poderá acrescentar com as questões apropriadas. A pesquisa exige ainda, visão interdisciplinar, com a intenção de mensurar todas as particularidades que circundem a ação. Como espécie de verificação ambiental o EIA é tido como um dos mais consideráveis mecanismos de desenvolvimento econômico-social, com a conservação da qualidade ambiental.

O RIMA deverá ser difundido, retratando as resultantes para que sejam debatidas junto aos cidadãos em audiência pública (artigo 16 da Resolução CONAMA 237/97), que autoriza a elucidação de dúvidas e a exposição de opiniões da sociedade, essencialmente as pessoas do local acometido pelo empreendimento.

A partir desse instante, o órgão ambiental fará sua declaração em relação à atividade e de suas consequências, positivas ou não, e em seguida deliberará acerca da expedição ou não da licença ambiental. 


\section{Personalidade Acadêmica Homenageada:}

Carlos Aurélio Mota de Souza (Universidade Ibirapuera - UNIB)

É imprescindível evidenciar que esse dispositivo tem como preceitos, os princípios da prevenção e da precaução, não tendo por escopo impossibilitar o desenvolvimento de atividades econômicas e sociais, mas ajustar o desenvolvimento à preservação ambiental. Desse modo, é expressiva sua importância, pois demanda operação conjunta do Poder Público, da sociedade e da comunidade científica, com o propósito de se conjugarem em um objetivo comum, o de estimular o desenvolvimento social e econômico à subsistência do meio ambiente. (SIRVINSKAS, 2008, p. 152)

É primordial enunciar que a homologação da licença ambiental, será possível mesmo que o EIA seja contrário. Fica identificada, com esta possibilidade, o incondicionalismo da administração pública para conceder ou não a licença ambiental. Diante disso, ocorrendo algum dano ao meio ambiente, e, nada obstante, se a atividade colabora para com o desenvolvimento socioeconômico, é possível que o Poder Público permita a atividade, desde que embase sua decisão. (FIORILLO, 2009, p. 144).

Acrescente-se constatar que o órgão público, e, por via de retorno, os servidores públicos, responderão objetivamente pelas lesões que a decisão administrativa vier a provocar, independentemente de ter sido baseada no estudo de impacto ambiental (a equipe multidisciplinar, como já se apontou, responderá sob a modalidade subjetiva ou culposa). A Constituição Federal foi expressa no sentido de que as pessoas jurídicas de Direito público e as de Direito privado prestadoras de serviços públicos responderão pelos danos que seus agentes nessa qualidade causarem a terceiros, assegurado o direito de regresso contra o responsável nos casos de dolo ou culpa (art. 38, § $6^{\circ}$ ).( MACHADO, 1996, p. 181).

De outra forma, se o EIA/RIMA revela-se contrário, integralmente ou em parte, incumbirá à Administração, em concordância com fatores de interesse e conveniência, avaliar a concessão ou não da licença ambiental, posto que, o desenvolvimento sustentável é princípio orientador da conservação do meio ambiente e do desenvolvimento da ordem econômica. Essa vicissitude retrata uma discricionariedade sui generis. Manifestamente, a concessão da licença deverá ser alicerçada legalmente, atacando cada um dos pontos que se mostraram impactantes 
Personalidade Acadêmica Homenageada:

Carlos Aurélio Mota de Souza (Universidade Ibirapuera - UNIB)

ao meio ambiente, sob pena de ferir o preceito contido no art. 37 da Constituição Federal. (FIORILLO, 2009, p. 74).

A Administração Pública ao conceder uma licença ambiental, mesmo diante de pontos desfavoráveis apontados pelo EIA, não poderá deixar de considerar os princípios da legalidade, impessoalidade, moralidade, publicidade e eficiência que a norteiam e, ainda, a responsabilidade objetiva pelos danos que sua decisão vier a causar.

\section{A Ética e a mORAL NA GESTÃo Ambiental e a CONCESSÃo de LICENCIAMENTO AMBIENTAL NA CONTRUÇÃO CIVIL EM DESCOMPASSO COM OS ESTUDOS DE IMPACTO AMBIENTAL}

\section{1 ÉTICA E MORAL NA GESTÃO PÚBLICA}

A percepção de moralidade no âmbito administrativo desponta com os primeiros passos do Direito Administrativo, o qual ganhou notabilidade após a Revolução Francesa e o fim do Estado Absolutista, época em que passam a serem assegurados os direitos individuais, fortalecendo-se os princípios da separação dos poderes, da legalidade, da distinção entre a pessoa do governante e do Estado, dentre outros institutos que ulteriormente dariam lugar ao Estado Moderno, tal qual denominado.

O vocábulo moral, na conceituação de De Plácido e Silva (2003, p. 930), "designa a parte da filosofia que estuda os costumes, para assinalar o que é honesto e virtuoso, segundo os ditames da consciência e os princípios de humanidade".

No conceito de Kant (2005), a Moral são as normas de conduta deontológicas que instituem as relações entre os indivíduos forçadas pelo hábito e que estruturam nossas práticas. Surge, portanto a partir da existência individual, sendo um juízo valorativo-subjetivo. Vázquez (2008) diz que a Ética é a Teoria ou a Ciência do comportamento moral dos homens em sociedade. Ele diz que a Ética é a 


\section{Personalidade Acadêmica Homenageada:}

Carlos Aurélio Mota de Souza (Universidade Ibirapuera - UNIB)

ciência que almeja investigar e explicar os tipos de experiência do comportamento humano moral.

A Constituição Federal ao indicar os princípios que devem ser considerados pelo administrador público no desempenho de sua função subsumiu entre eles o princípio da moralidade. Isso quer dizer que em sua atividade o administrador público deve obedecer aos princípios da conduta ética, confiável, reivindicando a obediência de modelos éticos, de boa-fé, de fidelidade, de normas que possibilitem a boa administração e a disciplina interna na Administração Pública (MARINELLA, 2005, p. 37). Moralidade administrativa está correlacionada à concepção de bom administrador.

O administrador, como ser humano atribuído de competência para atuar, deve, imperiosamente, diferençar o Bem do Mal, o Honesto do Desonesto. E ao exercer, não poderá desdenhar o componente ético da sua conduta. Desse jeito, não terá que dirimir simplesmente entre o legal e o ilegal, o justo do injusto, o conveniente e o inconveniente, o oportuno e o inoportuno, mas do mesmo modo entre o honesto e o desonesto. (MEIRELLES, 2012, p. 90).

Em razão ao princípio da moralidade administrativa, não será suficiente ao administrador o desempenho da rigorosa legalidade, ele deverá observar os princípios éticos de razoabilidade e justiça, pois a moralidade estabelece hipótese de validade de todo ato administrativo experimentado (MORAES, 2005, p. 296).

Indispensável, por conseguinte, a constituição de valor público por intermédio de uma nova gestão estratégica na área governamental, fundamentada em primeiro lugar, na filosofia de uma moderna responsabilidade ética para a administração pública com o objetivo de não consentir que a cidadania seja subtraída de seus direitos, consequentemente a ética deve estar em supremacia às moralidades individuais, tanto dos políticos eleitos, quanto dos funcionários públicos, protagonistas da estabilização do novo ideal de Gestão Pública, alicerçado na eficiência e eficácia como êxitos reais da coletividade, as quais exclusivamente se consumam a partir de políticas públicas compromissadas com os desejos populares. 


\section{Personalidade Acadêmica Homenageada:}

Carlos Aurélio Mota de Souza (Universidade Ibirapuera - UNIB)

\subsection{A GESTÃO AMBIENTAL E OS ATOS DE IMPROBIDADE}

Em se considerando o meio ambiente um patrimônio público de imensurável valia, não só para a população brasileira, mas para todo o mundo e para o futuro da vida, protegido expressamente no art. 225 da CRFB/88, dúvidas não há acerca da aplicabilidade da Lei federal ํㅜ 8.429/92 aos agentes públicos que, no exercício da função administrativa, causem ou se omitam em relação aos danos ambientais.

Na proporção em que a Constituição Federal prevê no seu capítulo VI (art. 225) a regra da proteção ao meio ambiente, e impõe a todos, e especificamente ao Poder Público, o dever de defendê-lo e preservá-lo para as presentes e futuras gerações, um ato administrativo que cause danos ao meio ambiente é hábil a ser enquadrado como ato de improbidade administrativa.

Por seu turno, no ato de improbidade administrativa, o dolo do agente público é assinalado pela ruptura dos deveres de honestidade, imparcialidade e lealdade, ou melhor, pela maculação do princípio da moralidade administrativa, concomitantemente ao atentado a outra regra primordial do sistema: o princípio da legalidade, visceralmente concernente com a conduta censurada pelo legislador (BERTONCINI, 2007, p. 171).

A Constituição Federal de 1988, em seu artigo 37, §4º, estipula que atos de improbidade administrativa sejam punidos política, funcional e administrativamente. Para dar eficácia a estão referido regulamento.

A intitulada Lei de Improbidade Administrativa Promulgada em 02 de junho de 1992 a Lei Federal №. 8.429, que, certamente, se dera a datar da promulgação da Constituição da República Federativa do Brasil de 1988, incessantemente referiuse à probidade administrativa, tornando "clara a necessidade de sancionar gravemente os atos de improbidade administrativa, estabelecendo como uma das metas da República Federativa do Brasil o controle e combate incessante da improbidade administrativa" (BERTONCINI, 2007, p. 23-24).

Os atos de improbidade encontram-se nos artigos $9^{\circ}, 10$ e 11 da Lei $n^{\circ}$ 8.429/92. Esses dispositivos legais constituem a tipificação dos atos de improbidade administrativa por intermédio de duas técnicas legislativas. A primeira, mencionada 


\section{Personalidade Acadêmica Homenageada:}

Carlos Aurélio Mota de Souza (Universidade Ibirapuera - UNIB)

no caput dos dispositivos tipificadores da improbidade, considera-se a utilização de pontos de vista jurídicos indefinidos, encontrando-se como dispositivo apropriado ao enquadramento do interminável número de ilícitos suscetíveis de serem realizados, os quais são frutos inexoráveis da singularidade humana.

A segunda, no que lhe diz respeito, foi empregada na forma de numerosos incisos que compõem os arts. 9ำ, 10 e 11, referindo-se a previsões específicas ou suscetíveis a integração das situações que correntemente consubstanciam a improbidade, que, além de descomplexificar a percepção das convicções indeterminadas veiculadas no caput, tem natureza exemplificativa, o que decorre do próprio uso do advérbio "notadamente".

Os atos de improbidade foram reunidos em três gêneros pela Lei de Improbidade Administrativa a saber: (i). atos que importam em enriquecimento ilícito, previstos no artigo 9o; (ii) atos que causam prejuízo ao erário, estabelecidos no artigo 10; e (iii) atos de improbidade que atentam contra os princípios da Administração Pública, na forma do artigo 11.

Vale evidenciar ser entendimento harmonizado na doutrina e na jurisprudência que os comportamentos previstos nos artigos 9o a 11 da Lei de Improbidade fundam uma mera demonstração, não finalizando outras conjunturas passíveis de contextualização, que poderão ser adaptadas nas fórmulas genéricas traçadas pelos artigos relacionados.

Desta forma, pode-se encontrar equivalência do ato em um dos incisos dos artigos citados, possibilitando o ajustamento da situação fática à descrição legal, mas pode suceder que a situação fática não se adéque aos incisos, o que não quer dizer atipicidade do procedimento ímprobo (TURRA SOBRANE, 2005, p. 50), sendo capaz de a adaptação ser feita com fundamento na descrição geral do caput do artigo correlato.

Ademais três categorias, consoante com José dos Santos Carvalho Filho (2013, p. 1.083), a Lei federal o 10.257/2001 (Estatuto da Cidade), em seu art. 52, concebeu uma quarta ao determinar que determinados atos ou omissões relacionadas à ordem urbanística representam atos de improbidade, assentindo aí a aplicação da Lei 8.429/92. 


\section{Personalidade Acadêmica Homenageada:}

\section{Carlos Aurélio Mota de Souza (Universidade Ibirapuera - UNIB)}

É de se notar que a tipificação legal, a começar da aplicação das duas técnicas legislativas anteriormente assinaladas, institui que os tipos dos incisos disponham relativa independência com referência à tipificação do caput dos artigos em evidência. Assim sendo o operador do direito só efetivara o trabalho de ponderar a conduta do agente público ímprobo quando não embater-se subsunção de conduta análoga nas figuras compreendidas nos incisos consignados (HENRIQUE FILHO, 2010, p. 115).

A natureza e os recursos naturais, instituem patrimônio nacional com predisposição constitucional no artigo $225, \S_{4}$, que do mesmo modo estabelece a sua proteção e exploração na forma da lei, sob condições que garantam a conservação do meio ambiente.

Nos termos de Emerson Garcia (2011, p. 204), patrimônio público é o complexo de bens e interesses de natureza moral, econômica, estética, artística, histórica ambiental e turística inerentes ao Poder Público.

No entendimento de Uadi Lammêgo Bulos (2011, p. 1584, grifo do autor), o bem ambiental descreve-se, num tertium genus, não suportando ser qualificado como bem público, nem privado, sendo um bem jurídico específico distinto daquele correlacionado ao direito de propriedade, assegurando que "quando o art. 225, caput, menciona 'bem de uso comum do povo' quer referir-se ao bem ambiental, que excede o sentido clássico de propriedade, no qual o proprietário usa, goza e dispõe, como quiser, da coisa que the pertence".

Em se considerando que os bens ambientais são de riqueza descomunal, enquadram-se os atos de improbidade dos quais ocasione qualquer circunstância de deterioração ao patrimônio ambiental nas penalidades dispostas na Lei 8.429/92, que no seu artigo 50 determina a reparação integral do dano ao patrimônio público por ação ou omissão, dolosa ou culposa, do agente ou de terceiro.

\subsection{OS IMPACTOS AMBIENTAIS DECORRENTES DA CONTRÇÃO CIVIL}

Consoante Macedo et Martins (2011), o ramo da construção civil nacional situa-se em processo contínuo de crescimento. Para o Sindicato da Indústria da 


\section{Personalidade Acadêmica Homenageada:}

Carlos Aurélio Mota de Souza (Universidade Ibirapuera - UNIB)

Construção Civil do Estado de São Paulo (2005), a construção civil é manifestamente uma das mais relevantes atividades para o desenvolvimento econômico e social, e, concomitantemente, é uma atividade desencadeadora de impactos ambientais. Côrtes et al. (2011, p. 385) evidenciam ainda um "quadro de atraso quanto à responsabilidade socioambiental" do setor, que, para isso, entre outras ações, deve edificar empreendimentos procurando diminuir os impactos ambientais relacionados.

O engrandecimento do setor de construção civil tem provocado considerável impacto, ruminando uma situação paradoxal, visto que a ascensão, por intermédio de obras civis, da melhoria das conjunturas urbanísticas de uma localidade, sincronicamente, amplia a demanda por matérias-primas naturais e, como sequela, provoca a geração de resíduos, acarretando impactos ambientais negativos (Paschoalin Filho et al., 2011). Kamimura (2012) salienta que os grandes empreendimentos adulteram o equilíbrio do meio biofísico e causam impactos socioeconômicos, culturais e ambientais de intensidades diversificadas. Para Rodríguez et al. (2011), a construção civil pode provocar, além dos impactos negativos, também impactos positivos, propiciando um incremento na qualidade de vida da sociedade pela inserção de infraestruturas distintas.

Os impactos ambientais advindos da construção são presumivelmente superiores em países em expansão do que em países desenvolvidos, por conseguinte, a indústria da construção nestes últimos não pode omitir cautelas com o meio ambiente e está impelida a conceber e a otimizar inovações para estar amoldada a atender aos crescentes encargos ambientais (Sakr et al., 2010).

Degani (2003) reputa que as empresas construtoras ostentam exclusivamente iniciativas preambulares voltadas à gestão ambiental quanto à adequação de recursos naturais e ao gerenciamento de resíduos. Por via de regra, a vinculação da construção civil com o meio ambiente é observada de forma análoga pelos vários autores. Resta evidente a relevância do setor para o desenvolvimento econômico e social, entretanto, visualiza-se a inevitabilidade no defrontamento dos problemas ambientais do setor. 


\section{Personalidade Acadêmica Homenageada:}

Carlos Aurélio Mota de Souza (Universidade Ibirapuera - UNIB)

A gestão efetiva dos aspectos ambientais exerce papel fundamental nesse cenário, devendo o Estado a partir de seus órgãos ambientais supervisionarem as obras e unicamente conceder licenças quando dispuserem de total segurança com relação aos riscos ambientais do empreendimento.

$\mathrm{Na}$ contramão do exposto, diversos empreendimentos iniciam-se sob a proteção de alvarás de construção expedidos irregularmente em contrariedade à lei local vigente, ou ainda, em descompasso com os estudos ambientais prévios, ainda que, como anota Hely Lopes Meirelles "que o alvará de licença para construir traz em si a presunção de legitimidade e de definitividade de sua concessão" (2000, p. 191).

Todavia, é dever do Poder Judiciário quando instado, no intuito de preservar o direito fundamental ao meio ambiente ecologicamente equilibrado, suspender atividades que considerar nocivas ao meio ambiente, nem que para isso reduza o alcance de outros direitos fundamentais, como o da propriedade privada e do livre exercício da atividade econômica, pouco importando se há concessão de lavra em favor do construtor ou licença emitida em seu favor.

Portanto, as atividades laborativas e o livre exercício dos direitos de propriedade, arrolados como garantias individuais previstas na Constituição Federal de 1988, não podem imperar em absoluto, mormente quando contrapostos ao interesse público, como o é a proteção dispensada pela Carta Maior ao meio ambiente.

A licença ambiental, portanto, não assegura ao seu titular a manutenção do status quo vigorante ao tempo de sua expedição, sujeita que se encontra a prazos de validade. Mesmo se inexistentes irregularidades na outorga da licença ambiental, caso o recomende o interesse público e em benefício da sociedade, poderá o ato ser revisto.

Em sendo, portanto, de interesse difuso a questão ambiental, a interferência do Poder Judiciário em regra se dá a partir de Ação Civil Pública, conforme disposto no inciso I do Art. $1^{\circ}$ da Lei 7.347/1985, em que normalmente se busca a concessão de liminar para barrar a continuidade da atividade degradante, além de outras sanções previstas em lei, sendo a primeira, medida imediatamente aplicável pelo 


\section{Personalidade Acadêmica Homenageada:}

Carlos Aurélio Mota de Souza (Universidade Ibirapuera - UNIB)

Poder Judiciário, especialmente quando o pedido vem escudado com a prova da lesão, através de documentos que corroboram as alegações apresentadas, sobretudo se indicada a possibilidade da continuação do dano ambiental até o julgamento final da lide.

\section{CONCLUSÃO}

A resposta encontrada no Relatório Brundtland para a conservação dos recursos ambientais foi o desenvolvimento sustentável como um novo modelo que propõe a satisfação das primordialidades atuais da população, tendo em vista a dimensão social, econômica e ambiental do meio ambiente.

O vocábulo "desenvolvimento sustentável" é tido como uma nova ordem mundial, visto que não basta desenvolver-se, sendo necessário que o avanço econômico, seja sustentável, daí a importância de harmonização entre desenvolvimento sustentável e crescimento econômico. Por consequência, o desenvolvimento sustentável deve ter a atuação da sociedade, e o planejamento territorial, intentando à estabilidade entre a economia e o meio ambiente.

Em que pese serem os dispositivos da Política Nacional do Meio Ambiente, hipoteticamente eficientes, considerando-se ser a legislação ambiental brasileira uma das melhores do mundo, percebe-se que não são eficientes para que se obtenha desenvolvimento sustentável. Pois o ordenamento jurídico outorga a alguns cidadãos a colocação de servidores públicos, os quais são revestidos de poderes a eles legitimamente concedidos pela sociedade para que, em nome desta, administrem o patrimônio público em benefício deste corpo social, devendo esta atuação estar disciplinada pela moralidade, pela ordem, pela igualdade, por políticas sérias que disponham o dinheiro público em benefício dos cidadãos, reais senhores da coisa pública, contudo os atos de improbidade são rotineiros.

À vista disso, é cediço que não bastam as normas punitivas através da intervenção do Estado, mas que são necessárias políticas públicas conjuntamente a essa intervenção, mais enérgicas para a construção de uma percepção ecológica 


\section{Personalidade Acadêmica Homenageada:}

Carlos Aurélio Mota de Souza (Universidade Ibirapuera - UNIB)

que aliada aos mecanismos de transformação de valores, possa contribuir de tal forma que o Meio Ambiente seja salvaguardado na presente geração, tendo em vista as futuras.

O Brasil conquistou um avanço significativo no tocante à democracia, legalidade, jurisprudência e um tímido, porém sensível, cuidado com a inserção do mínimo ético na gestão pública e no desenvolvimento de suas políticas.

A Constituição de 1988 fez elevar-se consideravelmente a imprescindibilidade de atitude ética na administração pública, a qual foi paradigmática e decisiva para a instituição do novo paradigma de gestão pública eficiente e eficaz, guiada por um Estado de Direito. Estado este, forçosamente promotor de Políticas Públicas concordantes com o mínimo ético habilitado a ser considerado efetivamente um estado democrático e ético.

Assim sendo, a Constituição se mostra fundamental para materializar as prioridades do Governo. Entretanto, é mister ressaltar que merece atenção especial a avaliação da inserção ética no planejamento das ações realizadas pelo gestor da máquina pública.

Propõe-se, consequentemente que a formulação de políticas públicas e as deliberações administrativas não sejam domínio de uma única pessoa, claramente porque estas fazem parte de um procedimento coletivo de múltiplas etapas sequenciais e simultâneas. Aqui destacamos que as decisões administrativas se passam em meio a demasiadas interações pessoais nas quais se busca não só algum grau de colaboração, mas mormente compartilhamento de valores éticos.

É forçoso acentuar que as morais individuais ou as heranças pregressas culturais sejam transformadas por uma conduta ética, corporificada pelo meio do alcance de verdadeiros valores coletivos que deverão ser refletidos por todos: gestores, sociedade, políticos, entidades religiosas, por fim, todo o grupo social.

A reflexão em relação a inserção ética nas recomendações e planejamentos das políticas públicas obviamente contribui para uma gestão pública eficaz e eficiente. Explicitando cientificamente o que é moral o que é ética, buscou-se ultrapassar o senso comum, desnudando o uso corriqueiro desses termos pelos quais se valem do discurso para enganar o cidadão. 
Personalidade Acadêmica Homenageada:

Carlos Aurélio Mota de Souza (Universidade Ibirapuera - UNIB)

A argumentação sobre a introdução da ética na construção das políticas públicas é de suma relevância para toda sociedade brasileira, pois somente mediante a adoção efetiva desse padrão o país poderá eliminar a desigualdade social que $o$ aflige.

A atividade administrativa tem como motivo a gestão do bem comum e do bem estar social, o qual exclusivamente pode ser alcançado dentro de uma ordem pública, devendo-se acatamento às normas e aos princípios constitucionais.

Desta forma, o patrimônio público, principalmente o patrimônio natural como um todo, é concernente a todos os cidadãos de forma democrática e justa, pressupondo-se, desta forma, que é dever de todos cuidar por sua preservação.

Saliente-se, por fim, em que pese o valor da instituição de normas, não é pura e exclusivamente através de leis que os atos de improbidade inerentes aos bens ambientais serão dissipados no Brasil, mas sim, mediante o fortalecimento de suas Instituições que possam fomentar uma real mudança de valores morais e éticos nos agentes públicos.

\section{REFERÊNCIAS}

Constituição Federal de 1988. Disponível em: <www.planalto.gov.br/ ccivil_03/.../constituiçao.htm>. Acesso em: 07 ago. 2018.

. Lei n. 6.938 , de 31 de agosto de 1981. Dispõe sobre a Política Nacional do Meio Ambiente, seus fins e mecanismos de formulação e aplicação e dá outras providências. Disponível em: <www.planalto.gov.br/ccivil/L6938.htm>. Acesso em: 08 ago. 2018.

. Lei n. -7.347 , de 24 de julho de 1985. Disciplina a ação civil pública de responsabilidade por danos causados ao meio-ambiente, ao consumidor, a bens e direitos de valor artístico, estético, histórico, turístico e paisagístico (VETADO) e dá outras providências. Disponível em:< http://www.planalto.gov.br/CCivil_03/leis/L7347orig.htm>. Acesso em: 09 ago. 2018.

. CONAMA. Resolução n.o 357, de 17 de março de 2005. Disponível em: <www.mma.gov.br/port/conama/res/res86/res0186.html>. Acesso em: 08 ago. 2018. 
Personalidade Acadêmica Homenageada:

Carlos Aurélio Mota de Souza (Universidade Ibirapuera - UNIB)

. CONAMA. Resolução n.o 001, de 23 de janeiro de 1986. Disponível em: <www.mma.gov.br/port/conama/res/res86/res0186.html>. Acesso em: 08 ago. 2018.

Resolução n.o 237, de 25 de março de 1997. Disponível em: <www.mma.gov.br/port/conama/res/res97/res0237.html>. Acesso em: 08 ago. 2018.

ARAÚJO, V. M.. Práticas recomendadas para a gestão mais sustentável no canteiro de obras. 2009. 231 p. Dissertação (Mestrado em Engenharia) - Escola Politécnica, Universidade de São Paulo, São Paulo, 2009.

BARBIERI, José Carlos. Gestão ambiental empresarial: conceitos, modelos e instrumentos. 2 ed. atual. e ampl., São Paulo: Saraiva, 2007.

BECKER, Dinizar Fermiano. A contradição em processo: o local e o global na dinâmica do desenvolvimento regional. Em BECKER, D. F.: WITTMANN, M. L (orgs). Desenvolvimento regional: abordagens interdisciplinares, 2. ed. Santa Cruz do Sul: Edunisc, 2008.

BERTONCINI, Mateus. Ato de Improbidade Administrativa: 15 anos da Lei 8.429/92. São Paulo: Editora Revista dos Tribunais, 2007.

BULLOS, Uadi Lammêgo. Curso de Direito Constitucional. 6.ed. rev. e atual. São Paulo: Saraiva, 2011.

CARVALHO FILHO, José dos Santos. Manual de Direito Administrativo. 26.ed. São Paulo: Atlas, 2013.

CÔRTES, A. M., Romano, C. A. e Barros Jr., P. A. (2011), Instrumentos de apoio à inovação tecnológica no Paraná: disponibilidade e uso nas empresas do arranjo produtivo local (APL) de software de Curitiba, Sistema \& Gestão, Vol. 6, No. 4, pp. 447-462.

DANTAS, Thiago Braga. Decrescimento econômico: a natureza como limite do crescimento e o novo contexto da economia verde. In: Sustentabilidade ambiental [recurso eletrônico]: estudos jurídicos e sociais. CUNHA, Belinda Pereira da, AUGUSTIN, Sérgio (Orgs). Dados Eletrônicos - Caxias do Sul, RS: Educs, 2014.

DEGANI, C. M., Sistema de gestão ambiental em empresas construtoras de edifícios, Dissertação de Mestrado em Engenharia Civil, Escola Politécnica, Universidade de São Paulo, São Paulo, SP, 2003.

FIORILLO, Celso Antonio Pacheco. Curso de Direito Ambiental brasileiro. 12 ed.rev. atual e ampl. São Paulo: Saraiva, 2011.

GARCIA, Emerson; ALVES, Rogério Pacheco. Improbidade Administrativa. 6.ed. Rio de Janeiro: Lumen Juris, 2011. 
Personalidade Acadêmica Homenageada:

Carlos Aurélio Mota de Souza (Universidade Ibirapuera - UNIB)

HENRIQUE FILHO, Tarcísio. Improbidade administrativa ambiental. Belo Horizonte: Arraes Editores, 2010.

KAMIMURA, K. H., Estruturas de gestão ambiental utilizadas na fase de instalação de empreendimentos de infraestrutura: análise comparativa em casos de obras lineares, Dissertação de Mestrado em Tecnologia Ambiental, Instituto De Pesquisas Tecnológicas do Estado de São Paulo, São Paulo, SP, 2012.

KANT, Immanuel. Fundamentação da Metafísica dos Costumes. Martin Claret. $1^{\underline{a}}$ edição. 149 páginas. 2005.

LIBRELOTTO, L. I.. Modelo para avaliação de sustentabilidade na construção civil nas dimensões econômica, social e ambiental (ESA): aplicação no setor de edificações. 2005. 371 p. Tese (Doutorado em Engenharia de Produção) - Programa de Pós-Graduação em Engenharia de Produção, Universidade Federal de Santa Catarina, Florianópolis, 2005.

MACEDO, A. T., et Martins, M. F. (2011), "A Sustentabilidade urbana na perspectiva das empresas construtoras em Campina Grande - PB", artigo apresentado no XII ENGEMA: Encontro Nacional sobre Gestão Empresarial e Meio Ambiente, São Paulo, SP, 5-7 de Dezembro, 2011.

MACHADO. Paulo Afonso Leme. Direito ambiental brasileiro. 6. ed. São Paulo: Malheiros, 1996.

MILARÉ, Édis. Direito do Ambiente: doutrina, jurisprudência, glossário. 8. ed. São Paulo. Editora Revista dos Tribunais, 2013.

MEIRELLES, Hely Lopes, Direito Administrativo Brasileiro, São Paulo, Ed. Medeiros, 2012.

Direito de Construir, 8ª ed., São Paulo: Malheiros, 2000.

MILLER, G. Tyler. Ciência ambiental. Tradução All Tasks. São Paulo. Thomson, 2007.

PASCHOALIN FILHO, J. A., KNIESS, C. T. e GRAUDENZ, G. S. (2011), "Gerenciamento e manejo sustentável de resíduos sólidos de construção e demolição (RCD): um desafio para o setor da construção civil", artigo apresentado no ENGEMA 2011: Encontro Nacional sobre Gestão Empresarial e Meio Ambiente, São Paulo, 5-7 de Dezembro, 2011.

RODRIGUES, Isabel Nader. Desenvolvimento sustentável. In: Direito, economia e meio ambiente [recurso eletrônico]: olhares de diversos pesquisadores. $\mathrm{RECH}$, Adir Ubaldo, BUTZKE, Alindo; GULLO, Maria Carolina (Orgs.). Dados eletrônicos. Caxias do Sul, RS: Educs, 2012. 
Personalidade Acadêmica Homenageada:

Carlos Aurélio Mota de Souza (Universidade Ibirapuera - UNIB)

RODRIGUES, Isabel Nader. Desenvolvimento sustentável. In: Direito, economia e meio ambiente [recurso eletrônico]: olhares de diversos pesquisadores. $\mathrm{RECH}$, Adir Ubaldo, BUTZKE, Alindo; GULLO, Maria Carolina (Orgs.). Dados eletrônicos. Caxias do Sul, RS: Educs, 2012.

SAKR, D.A., SHERIF, A. e El-HAGGAR, S.M. (2010), "Environmental management systems' awareness: an investigation of top 50 constractors in Egypt", Journal of cleaner production, Vol. 18, No. 3, pp. 210-218.

SACHS, Ignacy. Caminhos para o desenvolvimento sustentável. In: STROH, Paula Yone, (Org.). Rio de Janeiro: Garamond, 2002.

SILVA, de Placido e. Vocabulário Jurídico. Rio de Janeiro: Forense, 2003. SILVA, De Placido e. Vocabulário Jurídico. Rio de Janeiro: Forense, 2003.

SILVA, José Afonso da. Direito ambiental constitucional. 2 ed. São Paulo: Malheiros, 1995.

SILVA, Marcela Vitoriano e. O princípio da solidariedade intergeracional: um olhar do Direito para o futuro. Revista Veredas do Direito. Belo Horizonte, v.8, n. 16, p. 115146, jul./dez. 2011.

SIRVINSKAS, Luís Paulo. Manual de direito ambiental. 6. ed. rev. atual. e ampl. São Paulo: Saraiva, 2008.

VAZQUEZ, Adolfo Sanchez. Ética. Ed. Civilização Brasileira. 30ª edição. 2008.

VEIGA, José Eli da. Desenvolvimento sustentável: o desafio do século XXI. Rio de Janeiro: Garamond, 2010. 